\title{
Pedagogía teatral y exploración de la realidad: Un abordaje expresivo-concientizador en la formación de docentes
}

\author{
Theatrical Pedagogy and Exploration of Reality: An Expressive Approach That Causes \\ Awareness in Teacher Training
}

\section{Pedagogia teatral e exploração da realidade: uma abordagem expressiva-consciente na formação de professores}

Recibido • Received • Recebido: 24 / 08 / 2018

Corregido • Revised • Revisado: 29 / 01 / 2020

Aceptado • Accepted • Aprovado: 16 / 04 / 2020

\begin{abstract}
Resumen: La premisa que propone la creación teatral como práctica creadora, interdisciplinaria y disruptiva emana de la exploración y reflexión en torno a los aportes pedagógicos de la expresión y la creación teatral en la formación de docentes de educación primaria. Como propuesta pedagógica se enmarca en los procesos de formación de la carrera de Pedagogía de la Universidad Nacional de Costa Rica e integra temáticas de diversas disciplinas como la pedagogía, la psicología, así como distintas formas de expresión escénica como: el teatro, la pantomima, las máscaras y la expresión por medio del cuerpo; todas orientadas al logro de aprendizajes vivenciales e integradores, $y$ al desarrollo de las aptitudes artísticas, expresivas y creativas en el desarrollo integral de cada persona. Parte de una serie de procesos que involucran la observación, el análisis e interacción social en diversos contextos; se recrea la realidad desde una perspectiva crítica, concibiendo la cotidianidad y el contexto social, como fuentes de información y, al mismo tiempo, como recursos expresivos favorecedores de la construcción de una vasta gama de conocimientos mediante experiencias vivenciales. Desde la pedagogía teatral se propone un acercamiento a la expresión y a la creación teatral, concebidas como elementos detonantes para el estudio, análisis y recreación del amplio espectro de situaciones que concede la realidad. Se aborda la aplicación de estos recursos expresivos en la mediación pedagógica, considerando las particularidades espaciales y culturales que caracterizan cada contexto observado. Finalmente, se plantea una serie de reflexiones en torno los primeros logros de la propuesta, el impacto en la formación pedagógica y en el desempeño futuro de los grupos profesionales de este campo.
\end{abstract}

Palabras claves: Realidad; observación; creación teatral; estudio crítico; mediación pedagógica. 
http://doi.org/10.15359/ree.24-2.21

ROR: https://ror.org/01t466c14 Universidad Nacional, Costa Rica

http://www.una.ac.cr/educare

educare@una.cr

Abstract: The premise that proposes theatrical creation as a creative, interdisciplinary, and disruptive practice emanates from the exploration and reflection on the pedagogical contributions of theatrical expression and creation in the training of primary education teachers. As a pedagogical proposal, it is part of training processes in the teaching program of the National University of Costa Rica and integrates themes from various disciplines like pedagogy and psychology. This training also incorporates distinct forms of scenic expression such as theatre, pantomime, masks, and expression through the body. The training is oriented towards the achievement of experiential and integrative learning and the development of artistic, expressive, and creative skills in the integral development of each individual. It starts from a series of processes that involve observation, analysis and social interaction in different contexts; reality is recreated from a critical perspective, conceiving the everyday life and the social context as sources of information and, at the same time, expressive resources, which favor the construction of a broad range of knowledge through experiential experiences. Theater pedagogy proposes an approach to theatrical expression and creation, conceived as triggers for the study, analysis, and recreation of the broad spectrum of situations granted by reality. The application of these expressive resources in pedagogical mediation is addressed by considering the spatial and cultural particularities that characterize each observed context. Finally, a series of reflections is proposed regarding the first achievements of the proposal and the impact on pedagogical training and the future performance of professional groups in this field.

Keywords: Reality; observation; theatrical creation; critical study; pedagogical mediation.

Resumo: A criação e implementação dessa premissa emana da exploração e reflexão pedagógica em torno das contribuições pedagógicas da expressão e da criação teatral na formação pedagógica de professores do ensino fundamental. Como proposta pedagógica, se enquadra nos processos de formação da carreira de Pedagogia da Universidade Nacional da Costa Rica. Integra temáticas de diversas disciplinas, como a pedagogia, a psicologia, bem como diferentes formas de expressão cênica como: o teatro, a pantomima, as máscaras e a expressão por meio do corpo, orientadas à realização de aprendizagens vivenciais e integradoras e ao desenvolvimento das aptidões artísticas, expressivas e criativas no desenvolvimento integral de cada pessoa. Parte de uma série de processos que envolvem observação e interação em diferentes contextos, bem como análise e criação teatral. A realidade é recriada a partir de uma perspectiva crítica, concebendo o meio social e o cotidiano como recursos didáticos que garantem uma ampla gama de conhecimentos, possibilidades e experiências de aprendizagem. Desde a pedagogia teatral, se propõe uma aproximação à expressão e criação teatral, concebidas como elementos detonantes para o estudo, análise e recreação do amplo espectro de situações que concede a realidade. Aborda-se a aplicação destes recursos expressivos na mediação pedagógica, considerando as particularidades espaciais e culturais que caracterizam cada contexto observado. Finalmente, uma série de reflexões em torno as primeiras realizações da proposta, o impacto na formação pedagógica e no desempenho dos futuros pedagogos.

Palavras-chaves: Realidade; observação; criação teatral; estudo crítico; mediação pedagógica. 


\section{Introducción}

Para comprender el propósito preliminar de esta experiencia expresivo-pedagógica, es preciso señalar que, como en toda exploración, la génesis o idea inicial siempre emerge de la necesidad de formular y poner en práctica metodologías innovadoras e inclusivas, capaces de provocar cambios y mejoras en diversos procesos. En este caso en particular, una propuesta de formación orientada a detonar, en las futuras generaciones de docentes, procesos de análisis y toma de conciencia sobre temas esenciales que inciden en la realidad social y, consecuentemente, en su futura labor educativa. Desde esta premisa que propone la creación teatral como práctica creadora, interdisciplinaria y disruptiva, se pretende amalgamar una serie de saberes que nutren la pedagogía, desde la dimensión lúdica y expresiva. Tal es el caso del juego escénico como recurso metodológico expresivo y fundamental para gestar, mediante la creación teatral, un acercamiento sensible, crítico y propositivo a la realidad.

Desde esta perspectiva, el juego escénico o teatral adquiere un alto valor pedagógico, porque permite desarrollar, globalmente, un conjunto de actitudes, procedimientos y conceptos interdisciplinarios que no se podrían trabajar de manera aislada y que ayudan al estudiantado a tomar conciencia de la realidad social y cultural que caracteriza su entorno.

\section{Aproximación a la realidad desde la pedagogía}

La pedagogía como elemento esencial de los procesos educativos constituye una de las áreas del conocimiento más dinámicas y versátiles, debido a su constante interacción con otras disciplinas y campos del conocimiento. Esta plasticidad le concede la posibilidad de nutrirse de diversos saberes y adaptarse a nuevos paradigmas, en una sociedad caracterizada por una vertiginosa y necesaria transformación, que demanda nuevas formas de leer e interpretar la realidad y el mundo circundante.

Desde una visión compleja e integral, la pedagogía es en primera instancia "un acto de libertad, de equidad de género, de creatividad, de colaboración, de alegría, de placer, de sentido del humor, de intuición, de espiritualidad, de estética y de arte..." (Flores Davis et ál., 2009, p. 63). Por lo tanto, la pedagogía como constructo sociohistórico debe concebirse y transformarse en función de su ámbito de acción o contexto. En este sentido, la pedagogía debe responder a esta transformación, enfrentando uno de los principales retos: concebir y consolidar el conocimiento desde una dimensión compleja, derribando los límites entre las distintas áreas y así poder apreciar las múltiples relaciones, las causas y los efectos de cualquier fenómeno, de manera que podamos abordar los problemas sociales con una visión integradora y global. Una realidad estrechamente interconectada con lo que acontece aquí y ahora, y que influye de forma directa en la colectividad. Sobre esta coyuntura Miranda Calderón y Cubillo Jiménez (2010) advierten: 
http://doi.org/10.15359/ree.24-2.21

ROR: https://ror.org/01t466c14 Universidad Nacional, Costa Rica

http://www.una.ac.cr/educare

educare@una.cr

Los nuevos tiempos nos sitúan hoy ante un acelerado proceso de cambios que ha modificado la forma en que estaba organizado el mundo. Cambios que inevitablemente inciden en la educación y que nos obligan a transformar, de forma dinámica, prácticas, teorías, modelos pedagógicos y contenidos. Pero sobre todo, nuestros supuestos epistemológicos y ontológicos como pedagogos y a la luz de una nueva sociedad del conocimiento. (p. 174).

Quizás una de las limitaciones que ha caracterizado a la pedagogía tradicional constituye el hecho de concentrar las decisiones y la ejecución de la metodología en el docente o la docente, perdiendo de vista la cognición como punto central del acto pedagógico y al estudiantado como persona actora principal de este mismo. Esta condición repercute fundamentalmente en cada uno de los roles de quienes participan en los procesos de aprendizaje, tanto estudiantes como pedagogos y pedagogas, al limitar las posibilidades para que ambos exploren nuevas formas de construir aprendizajes más orgánicos y orientados a la reflexión pedagógica.

El aprendizaje vivencial requiere de un proceso elaborado, y no simplemente de la experimentación. Hay que verbalizar las experiencias, reflexionarlas, generalizarlas para poder ser aplicadas. Nuestra investigación ha puesto de manifiesto la importancia de este proceso de experimentar-verbalizar-revisar-volver a experimentar. (Navarro Solano, 2007, p. 167)

En la actualidad, distintas propuestas educativas basadas en nuevos enfoques pedagógicos apuntan al compromiso de integrar la expresión y el arte en la mediación, como elementos detonantes para lograr aprendizajes más inclusivos, vivenciales, integrales y concebidos en un amplio espectro de posibilidades cognitivas, que ubican a cada estudiante como protagonista del proceso, concediéndole la oportunidad para proponer desde su lectura del mundo.

la educación del presente reclama nuevas/otras maneras de concebir y desarrollar los procesos de enseñanza y aprendizaje al interior de la escuela y no solo por la marcada influencia que las tecnologías de la información y la comunicación están ejerciendo en niños, niñas, jóvenes y personas adultas a la hora de acceder o construir conocimiento y sus posibilidades, sino por los nuevos desafíos que tiene el planeta entero en preservar su existencia, lo que exige la promoción de una formación humana en todos los niveles, pedagógicamente mediada, que potencie una evolución en la formas de inteligencia capaz de utilizar el dato, la información, el saber no solo para crear nuevos modos de relacionarnos armónicamente ser humano-naturaleza reconfigurando el sentido la vida misma. (Alzate-Ortiz y Castañeda-Patiño, 2020, p. 3)

Esto, sin duda, involucra un punto de ruptura para trascender la forma como hemos venido desarrollando los distintos procesos ligados al aprendizaje y, consecuentemente, la enseñanza. Representa una oportunidad para desarrollar procesos pedagógicos que propicien nuevas formas de aprender y expresar lo que aprendemos. En torno a esta dimensión del aprendizaje Miranda Calderón et ál. (2017, p. 51) expresan: 
Como seres aprendientes tenemos una relación única, vital y particular con nuestro entorno, lo que hace posible percibir y procesar información en forma intuitiva y sensorial. Es lo que llamamos una forma o estilo de aprender. Tan única e irrepetible como cada persona. De manera que cada vivencia y cada experiencia acumulada, se constituye en una serie de aprendizajes, que a su vez sirven de plataformas o nuevos puntos de partida hacia nuevos aprendizajes, ideas y conocimientos. Estos procesos sin duda, revisten de singularidad el acto de aprender y concebir conocimiento de forma individual o social.

Por lo tanto, la expresión, como función vital del aprendizaje, se convierte en una nueva forma de construir conocimientos más integrales, como lo señala Dinello (2006) al afirmar:

La pedagogía de expresión ofrece a cada sujeto la posibilidad de reencontrarse a sí mismo en las actividades ludocreativas y luego, específicamente desde su consecuencia y objeto creado, se realiza una articulación con diferentes contenidos, tanto cognitivos como estéticos y éticos. Tales animaciones pedagógicas corresponden a todo proceso de evolución personal con posibilidades de múltiples aprendizajes. (p. 8)

La experiencia del aprender consciente se vive de formas incomparables, de acuerdo con el ciclo que está viviendo cada aprendiente. Captamos la realidad desde nuestro propio universo, como lo menciona Menchén Bellón (2015):

La capacidad de captar la realidad es común a todas las personas, pero no siempre somos conscientes. Se trata de hacer una elección consciente de los actos, hechos, situaciones, sentimientos, vivencias, y desde tu energía interior crear nuevas posibilidades, intensiones y pensamientos. Se trata de decidir en qué mundo queremos vivir, siendo conscientes de esa elección. (p. 50)

Aquí reflexiono sobre el asombro del descubrirse en el aprendizaje y, en particular, sobre el asombro y la fascinación, así como el disfrute y el gozo de expresarlo por quienes aprenden, pues generan nuevas experiencias del mismo orden, con efectos y consecuencias transformadoras, tanto en el nivel de conciencia personal como en el plano de la conciencia colectiva o social.

\section{Exploración de la realidad desde la pedagogía teatral}

Pensar la pedagogía desde lo expresivo y lo escénico nos aproxima, necesariamente, al hecho teatral (Marcelo y Vaillant, 2018) como práctica sociocultural disruptiva capaz de traspasar los límites del espacio y el tiempo, y situarnos en otras realidades, para lograr develar aspectos críticos de la dinámica social. En torno a esta dimensión sociopedagógica de la pedagogía teatral, Vázquez Lomelí (2009) añade: 
La problematización dela acción dramática dinamizaygenera otrosinsumos-conocimientos que provocan la reflexión-conciencia. Las acciones dramáticas estarán cargadas de reflexión -social y humana-, porque las acciones (del personaje) fueron problematizadas pedagógicamente desde diversos enfoques y perspectivas disciplinarias, con el fin de comprender la acción social y humana. (p. 70)

En este sentido, la pedagogía teatral adquiere una función concientizadora, ya que, según Vieites (2017), esta noción nos permite concebir el hecho teatral como un detonante para la creatividad y el análisis de la realidad, asimismo Navarro Solano (2007) afirma que la acción teatral es:

Un medio privilegiado que desarrolla la creatividad, ya que requiere de la elaboración de nuevas situaciones y respuestas utilizando los recursos lingüísticos, corporales, musicales, gestuales, etc. El desarrollo creativo personal es fruto en parte de la creación de contextos creados por la práctica de la dramatización. (p. 166)

Esto no solo nos permite apreciar integralmente y desde diversos ángulos los fenómenos sociales, privilegiando nuevas formas de aprender, sino además proponer respuestas y soluciones creativas a dilemas o problemáticas sociales que nos plantea cada contexto. De esta manera, el teatro se transforma en un espacio de encuentro y análisis, como lo afirma González Parera (2012):

Sin duda, el teatro es un escenario de mensajes sociales y un vehículo de transmisión a lo largo de los tiempos. Es un espacio de encuentro inter y transdisciplinar. A través del teatro se viven conceptos históricos, sociales, políticos, psicológicos, literarios y todo aquello que encontramos en la vida misma. (p. 50)

Por otra parte, y desde la dimensión pedagógica, la acción teatral otorga la posibilidad de constituirse en un recurso dinámico y efectivo, que puede ser implementado en el abordaje de infinidad de temáticas y contenidos, en la mediación pedagógica de los distintos niveles de la educación formal y no formal, como lo describe Pérez-Aldeguer (2017):

Las artes escénicas poseen un gran valor para adentrarnos en un aprendizaje holístico; un aprendizaje que traspase barreras. Este tipo de aprendizaje conecta emoción y razón de una forma magistral ya que mediante las artes escénicas, los estudiantes son capaces de buscar soluciones a problemas «reales» (aprendizaje basado en problemas), crear proyectos que les motiven (aprendizaje basado en proyectos), disponer de interacciones saludables entre compañeros (aprendizaje cooperativo), tratando en todo momento el aprendizaje activo propio de estas metodologías y proporcionando un significado individual y grupal a su periodo formativo. (p. 2) 
Esta dimensión pedagógica del teatro nos concede la posibilidad de enriquecer los procesos de cognición, mediante la exploración de códigos y lenguajes escénicos que permitan transitar de la realidad a la fantasía y viceversa, y propiciar, desde la imaginación y creatividad, la inspiración y creación de nuevos mundos y realidades orientadas a una necesaria transformación de nuestro entorno.

\section{Estudio de la realidad: Un abordaje crítico}

El concepto realidad constituye uno de los constructos sociales más complejos y abstractos y en el que convergen el tiempo y espacio. Presupone un conglomerado de múltiples dimensiones que ubican al ser humano como un aprendiente de su entorno, como lo señala Menchén Bellón (2015) al afirmar que cada persona es capaz de crear una realidad propia. En torno a esta noción Miranda Calderón (2018) afirma:

La realidad es un elemento viviente y evolutivo que se adapta y se modifica a sí mismo. Por lo tanto en esta trama de una realidad cambiante, construir una definición universal de realidad constituye un asunto de infinito alcance pues concebirlo inevitablemente implica ligarlo a nuestra existencia, a cada una de nuestras realidades inmersas en su devenir. Es ser conscientes de la historización de lo que nos rodea, en nuestra corporeidad y en nuestro espacio-tiempo. (pp. 383-384)

La realidad como elemento condicionante de la dinámica social interviene en el devenir y ritmo de nuestras vidas, tanto en la dimensión individual como en la colectiva. Influye en las múltiples formas de percibir el mundo, imaginarlo, interpretarlo, comprenderlo, organizarlo y habitarlo con otros seres. Es decir, transformamos la realidad a partir de nuestra existencia y nuestra conciencia de ella. Por lo tanto, aproximarse a la realidad con una visión pedagógica implica valorar aspectos esenciales de nuestra cotidianidad desde lo cercano, lo familiar, lo comunal y lo imaginario, así como lo lejano y lo imaginario.

Las diversas formas de leer la realidad están intrínsecamente ligadas con nuestras experiencias, interacciones y valores, lo que implica que filtramos la percepción de la realidad a través de un vasto universo de representaciones que hemos construido desde nuestra propia vivencia y en interconexión con otros seres, estableciendo espacios de encuentro en los que predomina nuestra experiencia vital, así como la manera singular e irrepetible de percibir el mundo y la realidad.

Las relaciones entre realidad social y conocimiento de la realidad social constituyen un caso sumamente peculiar de las que se dan entre mundo y ciencia, ante todo, porque la realidad social es muy compleja, mucho más que la físico-natural, pues está impregnada 
de sentido, que configura su estructura y su funcionamiento. $Y$, en la misma línea, los individuos que la componen hablan, emiten mensajes complejos de los que depende su comportamiento y el de los demás; y lo hacen en una lengua (de entre una enorme variedad de ellas) que no ha creado ninguno de los hablantes, sino que todos han aprendido. (Beltrán Villalva, 2016, p. 122)

Desde la dimensión pedagógica, abordar el estudio de la realidad con una visión crítica implica, según Gómez Francisco (2010), una reorganización del mundo de representaciones, experiencias personales y parámetros axiológicos de cada persona, tanto en el plano individual como en el colectivo; modelados o determinados por los distintos condicionantes sociales, culturales y morales.

Esta noción nos permite obtener diversas miradas que nos acercan a cada realidad desde diversos ángulos, propiciando la reflexión sobre la actitud crítica y reflexiva, ante las diferentes problemáticas que presenta la realidad, ya que según Freire (2012), la práctica educativa crítica nos conduce a pensar y actuar de forma congruente, lo que implica un movimiento dinámico y dialéctico, entre lo que hacemos y lo que pensamos sobre ese hacer. Por lo tanto, no solo basta con observar la realidad, sino que nos compromete a ejercer el acto pedagógico con perspectiva crítica para poder transformarlo. Según (Miranda Calderón, 2015), esta visión compleja de nuestra impronta en la realidad presupone la interacción con otras nociones que abordan cada fenómeno social desde diversas miradas como la cultura, la geografía o la historia, lo que nos conduce a un análisis de la realidad desde una visión crítica y disruptiva. Desde esta visión crítica Miranda Calderón (2015) propone:

Como premisa de mediación pedagógica disruptiva para el estudio crítico de la realidad, la creación teatral permite explorar las diversas formas en que las personas interaccionan con su entorno y en un contexto espacio-tiempo. Permite identificar distintas percepciones en torno a situaciones particulares de la realidad, su naturaleza y los actores sociales que participan en ella. Como forma de expresión liberadora, la creación teatral rompe con las barreras que cada persona se impone con los distintos estereotipos y estigmas asignados por la sociedad sociales que de manera muy sutil impregnan conductas y actitudes, predeterminan roles y establecen relaciones de poder que a su vez inhiben el desarrollo pleno de cada persona. (p. 126)

Martínez Miguélez (2009) postula que los fenómenos físicos, biológicos, sociales, ambientales y políticos, tienen interconexiones, interdependencias, reciprocidades $y$, por tanto, es necesario y valioso considerar la coherencia integral, sistémica y ecológica de tales fenómenos; de lo contrario, los resultados del aprendizaje serán simples y aislados. Monroy et ál. (2016) añaden:

\section{8} Luis Alfredo Miranda-Calderón

Los artículos de la Revista Electrónica Educare del Centro de Investigación y Docencia en Educación de la Universidad Nacional, Costa Rica, se comparten bajo términos de la Licencia Creative Commons: Reconocimiento, № Comercial, Sin Obra Derivada 3.0 Costa Rica. Las autorizaciones adicionales a las aquí delimitadas se pueden obtener en el correo: educare@una.cr 
La complejidad del conocimiento se caracteriza por mirar la realidad de manera sistémica. La visión sistémica permite apreciar la realidad educativa como una estructura que hace posible valorar distintos componentes, elementos diversos, variedad de interacciones, diversidad de conflictos tanto en lo social como en lo económico y en lo ambiental. Abordar lo real; esto es, pretender el conocimiento de la situación y la condición educativa, reclama el empleo de saberes, habilidades, estrategias y actitudes diversas para conocer diferentes ángulos de dicha realidad. (p. 13)

\section{Contexto y realidad: Nuevos recursos didácticos}

Proponer la realidad como recurso y ámbito de estudio implica pensarla como una valiosa fuente de información para leer no solo el entorno físico, sino además el dinámico contexto social. A partir de esta visión, el tiempo y el espacio se establecen como coordenadas para la exploración de múltiples contextos, situaciones y lugares. Por lo tanto, cada espacio social obedece a una serie de condicionantes establecidos por la dinámica sociohistórica que ofrece una vasta gama de información para interpretar y recrear la realidad de diversas formas y utilizando distintos lenguajes.

Nuestra vida constituye una fuente constante de conocimientos, una asombrosa cantidad de información inscrita en nuestra existencia, incluso desde antes del nacimiento. La generamos sincronizadamente y somos parte de ella. Esta creación de conocimiento pasa por distintas etapas, una de ella es la sensorial, etapa que nos permite conocer el mundo a través de lo que percibimos a nuestro alrededor con nuestros sentidos y la intuición.

\section{La observación: Génesis de la premisa}

Captar la realidad no es solo limitarnos a observar su entorno natural, social o físico, sino además percibir su dinámica, lo que ocurre en ella y cómo le afecta. En este sentido, las relaciones causa-efecto, los acontecimientos y los condicionantes sociales son esenciales como elementos vitales para poder interpretarla. Según Miranda Calderón (2015):

la percepción del entorno y la realidad supone un estado de conciencia que nos permite interactuar de manera vital con diversos contextos, construyendo y deconstruyendo nuevas formas de mirar el mundo y de representar la realidad. Desde esta visión cada uno de nuestros sentidos, constituyen valiosas herramientas para descubrir y distinguir la vasta complejidad del mundo que nos rodea. (p. 124)

La observación es una forma por medio de la cual se establece un vínculo concreto, dinámico y permanente entre la persona que observa y la realidad, permite precisar y comprender la razón de los hechos y sus eventuales efectos, así como descubrir las múltiples interacciones que se producen dentro de cada realidad estudiada. Puede ser un evento natural o social, como lo describen Campos y Covarrubias y Lule Martínez (2012) al mencionar que el fenómeno: 
Se entiende como todo suceso natural o social que existe independientemente del observador; el fenómeno, es algo perceptible que se presenta como realidad objetiva en un espacio y tiempo, fiable de ser visto por sus atributos tangibles, por lo tanto, éste puede causar confusión al tratar de conocerle, de ahí que se diga que observar, no sólo es ver, sino analizar, siendo esto último [sic] el papel que debe jugar el investigador al momento de hacer la observación. (p. 50)

Como punto de inicio para la exploración de los fenómenos sociales, la observación se constituye en una herramienta concientizadora (Miranda Calderón, 2015), que nos sitúa frente a un universo infinito de posibilidades para percibir de forma sensorial, el entretejido social y la vasta gama de interacciones presentes en distintos escenarios o contextos.

La observación requiere de atributos para su aplicación, así como también el desarrollo de habilidades previas que establezcan las condiciones de manera tal, que los hechos observables se realicen en la forma más natural; es decir, sin que exista la intervención de juicios previos y de esta forma dar pie a prever la conducta que asumirá el investigador ante el fenómeno a observar; o sea, tomar en cuenta hasta donde sea posible, todos los elementos que puedan intervenir de forma directa o indirecta en el proceso de la observación. (Campos y Covarrubias y Lule Martínez, 2012, p. 51)

Las diversas formas de observar la realidad están intrínsecamente relacionadas con nuestras experiencias, interacciones y valores, lo que implica que filtramos la percepción de la realidad a través de un vasto universo de representaciones.

Desdeesta concepción, la observación debe realizarse mediante el uso de todos los sentidos y canales perceptivos, de tal modo que nos permita aprehender la realidad de una manera sensible y orgánica para su comprensión; en donde la intuición, los presentimientos, la incertidumbre y las dudas, son determinantes en cualquier investigación ya que nos da la posibilidad de percibir distintos matices de cada realidad y sí poder para recrearla. (Miranda Calderón, 2015, p. 63)

Al respecto, Cortés (2016) afirma:

Procurar una aproximación a la observación y a la escucha demanda un esfuerzo de indagación, acerca de la naturaleza de sus determinantes, sus límites y posibilidades, requiere también de un deseo de preguntar y preguntarse qué es lo que está pasando en este momento en la observación determinada. (p. 68) 
La realidad es infinita, no posee límites y traspasa las dimensiones del aquí y el ahora. Como observadores nos involucra de forma consciente e inconsciente. Menchén Bellón (2015) señala que "el observador selecciona aquello que le interesa, según sus deseos y grado de motivación. Una forma singular de captar la realidad es mirar a tu alrededor y ver lo que los demás no han visto" (p. 51).

Percibir la realidad como fenómeno social, pero esencialmente humano, implica una lectura sensible y crítica de nuestro entorno sociocultural. Una profunda mirada que posibilite la identificación y comprensión de la vasta constelación de situaciones y circunstancias sociales que, de forma aislada y compleja, influyen en cada contexto, como es el caso del escenario sociogeográfico que le delimita y sus implicaciones: la diversidad cultural, las interacciones entre las personas como actoras sociales, así como las situaciones críticas que inciden de forma constante (ver Figura 1). Estos condicionantes son factores esenciales, no solo porque determinan la dinámica social, sino, además, porque permiten analizar y proponer respuestas puntuales desde diversas perspectivas y disciplinas.

Desde la creación teatral, estos elementos pueden establecerse como circunstancias ideales para ser expresados y recreados mediante distintos lenguajes escénicos.

Figura 1: La percepción de la realidad debe involucrar una mirada abierta y flexible que nos permita reconocer condicionantes sociales

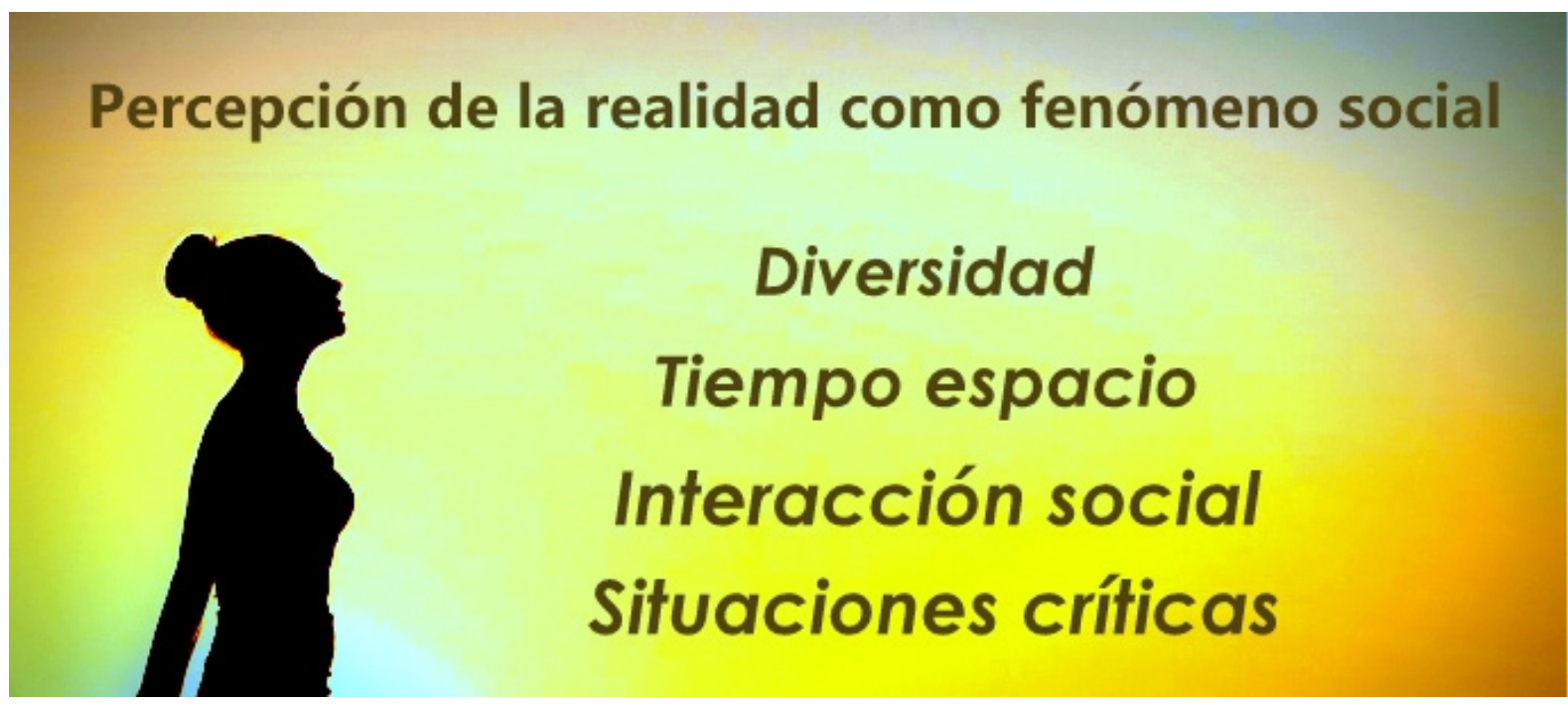

Nota: Elaboración propia. 


\section{El teatro: Un lenguaje para recrear la realidad}

Los lenguajes escénicos como elementos del universo teatral combinan lo verbal, lo no verbal y lo paraverbal, propiciando las condiciones para hacer posible distintas lecturas de una misma realidad. Miranda Calderón (2015, p. 128) propone:

el lenguaje teatral como una ruta para la exploración pedagógica del tejido social. Para ello considera indispensable concebir el juego escénico, como un recurso metodológico expresivo y fundamental, para mediar nuevas formas disruptivas de construir aprendizajes y detonar procesos de análisis que aborden temas esenciales que inciden en cada realidad estudiada.

de la Torre y Moraes (2005) sostienen que, por medio del teatro, nos aproximamos a un aprendizaje integrado, concibiéndolo como un proceso mediante el cual podemos construir nuevos significados, al mismo tiempo que mejoramos estructuras y habilidades cognitivas. Desde esta perspectiva, el juego escénico cobra un importante valor pedagógico porque propicia el desarrollo y fortalecimiento integral de una serie de actitudes, capacidades, habilidades y nociones interdisciplinarias que nos orientan y nos permiten tomar conciencia de la realidad social y cultural que caracteriza nuestro entorno. Visto como una metodología para la construcción de saberes, Moreno González (2016) afirma que el juego:

posibilita la simbolización y, según la capacidad de simbolización del sujeto este podrá jugar libremente juego y simbolización van por tanto estrechamente unidos y no solamente en infancia si no durante toda nuestra vida por incorporar el juego como parte de la mediación permite crear ese en arios donde la posibilidad que se concreta donde se disuelve nudos y se crean lazos de sus superan dificultades y donde se proyectan deseos. (p. 18)

De modo que, desde la pedagogía, el juego escénico o teatral se constituye en una herramienta para la exploración de procesos disruptivos de formación pedagógica ante la necesidad de inspirar nuevas metodologías, optimizar los procesos de aprendizaje y ser un aporte significativo a la formación pedagógica y cultural del estudiantado desde la expresión artística. Ese conocimiento obtenido a través de la experiencia sensible posee estética que deriva de la palabra aisthesis, cuyo significado es sensación, ese sentir, ese diálogo cognoscitivo individual y colectivo con el entorno. En este sentido, la memoria o evocación mediante los sentidos (sensorial) y la memoria de las emociones (emotiva), constituyen dos importantes baluartes para el proceso de simbolización, para la interpretación de personajes y, consecuentemente, para la recreación de diversas realidades y universos. 


\section{La creación teatral: Itinerario de la vivencia}

\section{La creación teatral como re-creación de la realidad}

En esta premisa prevalece la exploración pedagógica con una visión crítica, relacionada con la necesidad de expresar y representar diversos aspectos que caracterizan cada realidad, a través del lenguaje teatral. Involucra la creatividad como un componente indispensable para recrear lo observado y proponer visiones alternas que podrían dar respuestas a problemas sociales. Al respecto Moreno González (2016) señala:

La creatividad debe ser protagonista en cuanto que aporta una mirada crítica sobre la realidad colectiva y pretende buscar alternativas para que las cosas sean de otra manera distinta, mejor. Propone repensar el lugar de cada uno y el contexto resignificando tanto la propia identidad como la dimensión colectiva. La creatividad constituye una importante herramienta para la transformación social ya que permite le formular de manera crítica los significados propios y compartidos reconstruyendo sentidos alternativos. (p. 136)

La creación teatral propicia, de forma individual y colectiva, la exploración de lenguajes y formas de interpretar y representar la realidad inmediata, desde una postura crítica que va más allá de lo meramente estético. Trasciende prácticas educativas tradicionales y propicia la fusión de nuevas formas disruptivas de mediación pedagógica, que a su vez implican formas alternativas de comunicación, de evaluación, de motivación, de participación, de relación entre actores del proceso, de articulación y de organización, entre otras. A partir de esta noción, la mediación para la creación teatral puede complementar estas nuevas formas de abordar la observación y la adquisición de nuevos lenguajes para representar la complejidad social (fenómeno), conformada por la vasta gama de situaciones a que nos enfrenta la realidad y la forma cómo nos afecta. En esta dimensión Moreno González (2016) menciona:

La creación permite a las personas contactar un color definido con las barreras que cada uno se impone con los estereotipos y los estigmas sociales, de manera muy sutil. La imaginación puede ser utilizada para juzgar con los límites propios y ajenos y sobrepasar los ingresos es un espacio de creación y de ficción reinventarse y representarse de una manera diferente puede ser un buen camino para explorar otras opciones dar vida me vas ideas y proyectar nuevas realidades. (p. 53)

Las posibilidades expresivas que ofrece la creación teatral permiten que los sujetos observadores-creadores, así como todas las personas ligadas a la actividad, de manera consciente, nutran el proceso con las vivencias y los aprendizajes construidos a partir de la experiencia creativa. Por lo tanto, el tipo de mediación que se proponga debe privilegiar el desarrollo pleno de cada participante. 
http://doi.org/10.15359/ree.24-2.21

ROR: https://ror.org/01t466c14 Universidad Nacional, Costa Rica

http://www.una.ac.cr/educare

educare@una.cr

La mediación artística recupera algunos conceptos extensamente abordados desde la pedagogía, la psicología y el trabajo social como son: el desarrollo integral de la persona, rescatar las partes ... del sujeto y sus potencialidades, promover la elaboración simbólica -por tanto, la superación de conflictos inconscientes-y tomar conciencia de la situación actual iniciar un proceso de transformación y reinserción. (Moreno González, 2016, p. 18)

Desde la perspectiva de la mediación de la creación teatral como estrategia pedagógica, es fundamental partir de una metodología que integre no solo la creación teatral, en sí, como producto final, sino además las coordenadas o etapas previas que constituyen los insumos primordiales de la propuesta, tal es el caso de la observación, el análisis de la realidad y la exploración de recursos expresivos, en función del abordaje crítico.

Nuestra vida constituye una fuente infinita y constante de conocimientos, una asombrosa cantidad de información inscrita en nuestra existencia, incluso desde antes del nacimiento. La generamos sincronizadamente y somos parte de ella. Esta creación de conocimiento pasa por distintas etapas, una de ella es la sensorial, etapa que nos permite conocer el mundo a través de lo que percibimos a nuestro alrededor con nuestros sentidos y nuestra intuición. Desde esta perspectiva, el juego escénico o teatral adquiere un alto valor pedagógico, porque permite desarrollar globalmente un conjunto de actitudes, procedimientos y conceptos interdisciplinarios que no se podrían trabajar de manera aislada y que ayudan al estudiantado a tomar conciencia de la realidad social y cultural que caracteriza su entorno.

\section{El sujeto mediador: Observador-gestor del proceso de creación teatral}

En el desarrollo del proceso de creación teatral, el papel del sujeto mediador como guía es fundamental. Su visión general de este es esencial, lo que le permite guiar al grupo de sujetos observadores-creadores a través de las distintas etapas que dan origen a cada creación teatral. Funge como un ente facilitador que gesta una serie de situaciones que propician el análisis y la creación, fusionando saberes de la pedagogía y el juego escénico. Al mismo tiempo, está presente, activamente, como participante de las experiencias, de manera que se configura en un sujeto mediador-creador

La presencia del sujeto mediador-creador a lo largo del proceso de creación teatral es esencial, especialmente si consideramos que su rol implica una importante tarea de acompañamiento pedagógico. Al respecto, Mañón y Lorente (2003) proponen que el educador o educadora "camina junto" a alguien en la intencionalidad de lograr la autonomía de las personas con las que va a trabajar. Por lo tanto, es fundamental considerar aspectos que estos estudios señalan como primordiales, tal es el caso las capacidades y fortalezas de las personas con las que trabajan y no en las limitaciones o dificultades. El acompañamiento que el sujeto mediador brinde a cada ente observador-creador debe intentar comprender su mundo de 
representaciones y sus emociones, desde una actitud que le dé la posibilidad de escuchar más allá de las palabras, para, así, propiciar el diálogo para ayudar a comprender donde lo sitúa el sujeto y el contexto.

Para el sujeto mediador-creador, llevar a cabo el entrelazado de estas experiencias conducentes a la creación teatral debe representar, además, una oportunidad para crear una estrategia pedagógica innovadora que involucra un valioso proceso de observación y seguimiento de la creación artística, mediante una metodología flexible y libre. Esta metodología implica, a su vez, un acompañamiento para el desarrollo expresivo y pleno, que no solo se concreta con la puesta en escena, sino que se profundiza a través del abordaje crítico de la realidad representada. Como persona gestora del proceso, debe integrar las distintas dimensiones (Figura 2) que erigen la experiencia.

Figura 2: Dimensiones que intervienen en el proceso de la creación teatral

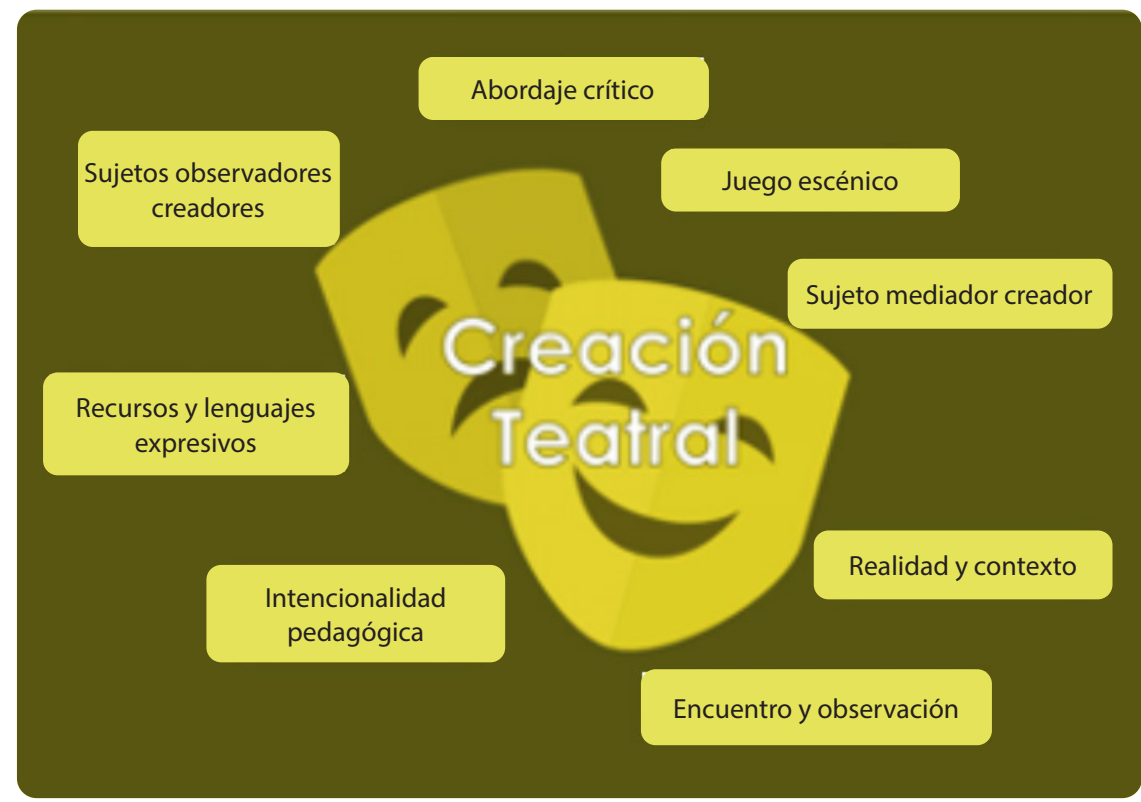

Nota: Elaboración propia.

\section{Coordenadas de la creación teatral}

En los procesos que dan origen a la creación teatral, cada propuesta suele elaborarse a partir de las ideas y percepciones de las todas las personas se conforman cada equipo de trabajo. Por lo tanto, su propósito no solo pretende presentar una obra teatral, sino construir, de forma creativa y dialógica, una propuesta escénica con sentido crítico, una creación entre todos los sujetos integrantes a quienes se les denominará sujetos observadores-creadores. 
Cada creación teatral es el producto de la observación y lectura de cada realidad o realidades observadas al inicio del proceso, de manera que cada creación se inspira en las distintas situaciones e historias de vida en su cotidianidad y de la vasta interacción social presente en los espacios colectivos. Todo esto expresado a través del lenguaje teatral y expuesto mediante representaciones simbólicas.

Como en todo proceso de creación, desde la mediación artística serán esenciales todos y cada uno de los recursos expresivos de las personas participantes, así como los elementos y situaciones que se suscitan durante el desarrollo de la experiencia de creación teatral. Se rescatan todas las aportaciones que se generan del análisis, de los ensayos, de la dinámica grupal propia del trabajo creativo y las múltiples interacciones guiadas y enriquecidas por el acompañamiento que el sujeto mediador brinda al grupo. En torno a este importante papel del facilitador, Laferrière (1999) menciona:

de la misma manera que un director de teatro utiliza todas las técnicas y todos los instrumentos teatrales que tiene a su disposición para demostrar su conocimiento y su competencia con sus actores, el enseñante utiliza todas las técnicas y todos los instrumentos a su disposición para demostrar su conocimiento y su competencia con los estudiantes. En ambos casos se sirven de la educación creativa y se les podría de finir como artistas-pedagogos. (p. 56)

Desde la dimensión pedagógica, la creación teatral no debe limitarse únicamente a la creación de un producto artístico. Debe concebirse como un espacio de convergencia o encuentro de diversas formas expresivas que proponen su propia metodología. Una serie de coordenadas y momentos (Figuras 2 y 3), por los cuales se transita para plasmar, mediante los lenguajes escénicos, aspectos de la realidad o de un fenómeno social observado, y que se consideran esenciales para abordar desde una visión crítica.

Figura 3: Coordenadas mediante las cuales se transita para poder plasmar aspectos de la realidad observada

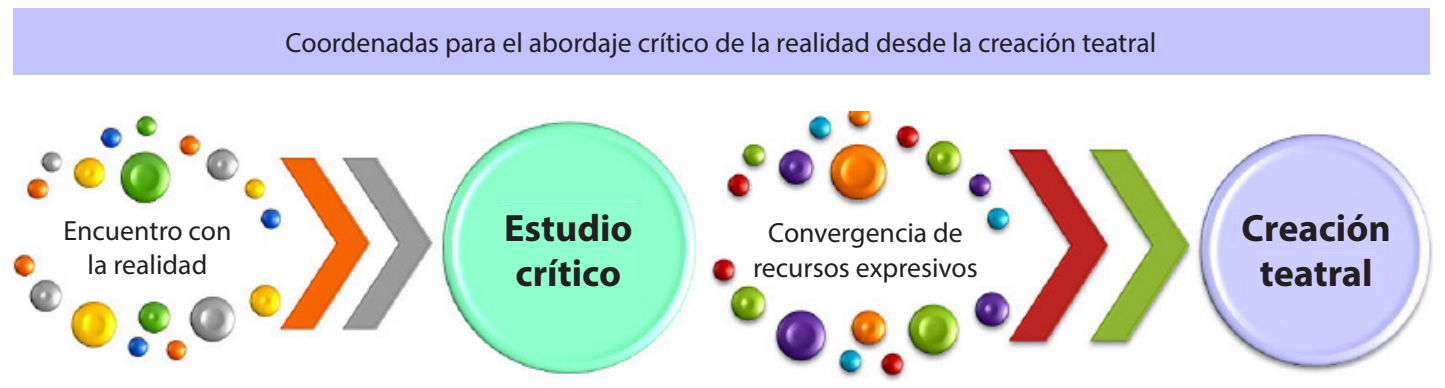

Nota: Elaboración propia. 


\section{Coordenada: Encuentro con la realidad}

La inicial, la más innegable y requerida. La observación de la realidad que se concreta en el encuentro de las personas observadoras-creadoras con las personas actoras sociales, confrontadas entre sí, a partir de la interacción social y en el espacio determinado. De esta manera se concibe la observación como una acción esencial y detonante para acceder a la realidad, se vislumbran, así, las distintas posibilidades que se gestan en cada espacio-tiempo.

\section{2a. Coordenada: Estudio crítico}

Para esta coordenada Miranda Calderón (2015) establece lo siguiente:

A partir de la realidad observada se genera un análisis que involucra un estudio crítico de las causas y efectos de lo observado, los factores determinantes, los distintos condicionantes tiempo-espacio, las percepciones de los observadores-creadores y su representatividad mediante la creación teatral, considerando para ello distintos lenguajes y formas de abordaje escénico de esa realidad. En algunos casos este análisis del fenómeno puede implicar un posicionamiento político por parte de cada observador-creador, que se expresa mediante la presencia de simbolismos en la creación escénica. (p. 125)

\section{3a. Coordenada: Convergencia de recursos expresivos}

La exploración y selección de los recursos expresivos en el lenguaje teatral (interpretación actoral, vestuario, movimiento, música, efectos visuales) constituye un punto fundamental en la creación. A esta coordenada corresponde la construcción de significados y simbolismos los cuales operan mediante la estructura de cada propuesta escénica, y en donde la presencia de intérpretes y espectadores confluyen nuevamente. Se analizan y se valoran las posibilidades y recursos escénicos en función del púbico y la temática. (Miranda Calderón, 2015, p. 128)

\section{4a. Coordenada: La creación teatral}

Constituye el fruto esencial de la experiencia y está relacionado con la relectura del contexto y la deconstrucción de la realidad, mediante la puesta en escena que se concreta en la creación teatral. Como producto creativo cada puesta en escena posee el potencial para expresar de múltiples formas, cómo interpretamos y afectamos nuestra realidad.

La creación teatral permite, a cada persona observadora creadora, explorar otros lenguajes para reinventarse y representarse de una manera diferente, dar vida a nuevas ideas y proyectar otras posibles realidades. 


\section{Discusión y reflexiones finales}

\section{Aprendizajes construidos desde la experiencia disruptiva}

Los aprendizajes y vivencias generados a lo largo del proceso constituyen el principal producto de esta experiencia, porque trascienden el espacio del aula universitaria, además inciden significativamente en la formación pedagógica de los futuros y futuras docentes, al brindarles la oportunidad de explorar y analizar la realidad desde la creación y expresión con un abordaje crítico; aspecto indispensable en su futuro desempeño educativo.

Como exploración pedagógica, esta experiencia permitió, a cada estudiante, valorar la trascendencia de su futura labor pedagógica, más allá de los elementos curriculares que inicialmente impulsaron la propuesta, ya que generaron una serie de conclusiones centradas en la necesidad y las posibilidades reales de impulsar otras formas de mediación pedagógica inclusiva que involucren, otros lenguajes, nuevas visiones del conocimiento, de la realidad y de un mundo que se puede construir y reconstruir desde el sentir y el aprender, confirmando la necesidad de potenciar las facilidades de cada estudiante, desde las prácticas docentes que consideren sus estilos de aprendizaje.

La experiencia desarrollada nos hace reflexionar sobre la necesidad de incorporar, en formación docente, prácticas inclusivas que propicien el uso del lenguaje estético y estimulen el desarrollo de la capacidad creadora mediante el juego y la expresión, para potenciar, desde un nuevo paradigma epistémico, el desempeño pedagógico de las futuras maestras y maestros, ya que como forma de expresión liberadora, el juego teatral rompe con las barreras que cada persona se impone con los distintos estereotipos y estigmas asignados por la sociedad.

Emprender una expedición hacia la búsqueda y construcción del conocimiento de la realidad, desde una posición concientizadora, nos sitúa ante una lectura necesariamente crítica de nuestra existencia física y espiritual, en la que el conocimiento sea concebido desde nuevas visiones o paradigmas que aborden no solamente nuestro accionar en la realidad, sino además sus implicaciones como factor determinante de nuestra coexistencia y como punto de partida para una renovada visión de nuestro entorno, en el cual los seres humanos somos aprendices y protagonistas, capaces de transformar la realidad.

La creación teatral o escénica, desde la dimensión pedagógica, constituye un valioso recurso que puede implementarse para valorar y analizar con nuestros propios límites y representaciones, la extensa gama de circunstancias sociales de la realidad, que de manera individual o colectiva inciden en nuestra forma de percibirla y vivirla, y supera, inclusive, los límites de cada sujeto espectador en un espacio en el que convergen la fantasía y la creación. 
El abordaje epistemológico que se propone, dentro de un modelo pedagógico humanístico y a partir de la expresión creativa, está basado en el postulado que afirma que aprendemos en forma constante, a lo largo de la vida y en continua interacción con la realidad, donde la capacidad de sentir, de asombro y de admiración es el fundamento esencial de la pedagogía. Desde esta perspectiva, el espacio de encuentro para la construcción e interacción de aprendizajes no debe reducirse exclusivamente a un aula o espacio escolar, sino extenderse a cada sitio y momento de la cotidianidad de quien aprende, es decir, conectar el conocimiento con cada realidad mediante el aprendizaje vivencial.

La creación teatral como producto de la práctica pedagógica disruptiva se orienta hacia la generación de nuevas interpretaciones de la realidad, así como hacia ideas o experiencias concientizadoras que buscan alcanzar sus propósitos desde visiones y formas diferentes a las tradicionalmente conocidas y aceptadas. Estas comprenden la exploración e incorporación de diversos ámbitos sociales, como lo son los sitios que conjuntan personas en constante interacción y concebidos como ricos espacios para el aprendizaje.

Crear experiencias creativas y compartidas siempre es una oportunidad de aprendizaje que propicia el diálogo y convivencia entre personas y sociedades diversas, fortalece sus vínculos sociales y afectivos. La exploración de lenguajes y el intercambio de representaciones, desde nuestro universo simbólico, crea lenguajes, metáforas y mensajes que cumplen funciones emocionales, sociales y biológicas fundamentales para la evolución en comunidad. También abre espacios de aprendizaje que nos permiten tomar conciencia de la realidad, favoreciendo la reconstrucción y transformación de esa realidad y para así caminar hacia una sociedad más inclusiva y justa.

La mediación pedagógica mediante la expresión creativa debe ser entendida como la integración de un conjunto de procesos cognitivos y expresivos que dan sentido a la vida y que privilegian la realización plena de la persona. Un proceso basado en la participación, la creatividad, la exploración y la relacionalidad del intercambio de experiencias que posibilita la transformación individual y social de nuestro entorno. Es la experiencia de lo que puede aportar el otro ser desde su contexto como un recurso indispensable. Una experiencia multidimensional, tridimensional, holística y vivencial.

El mundo-realidad ha sufrido cambios vertiginosos en los últimos tiempos. Cambios que ni siquiera pasaban por nuestra imaginación. Cambios que han tomado por sorpresa a todos los seres habitantes de este planeta y que nos involucra a todas y a todos, que se han filtrado en la totalidad de campos de la sociedad y que amenazan con una mayor desigualdad social, una fragmentación de la sociedad, peligros ambientales impensables, cambios en las formas de trabajo, en la conformación de nuevas estructuras de familia, en la inestabilidad y relatividad de las normas y en la diversificación de vida y culturas. 
Tomando como punto de partida este escenario social, es ineludible la concepción de nuevos paradigmas que permitan formular una pedagogía alternativa basada en el conocimiento presente en nuestro entorno social y físico. Paradigmas que rompan con la visión tradicional de dualidad $y$, por ende, mecanicista del aprendizaje; que concedan una visión integrada y compleja del mundo, dando paso así a una renovada perspectiva de la vida y del aprendizaje, en la que aprender sea una función vital e integral que puede transformar la totalidad de cada persona y, por lo tanto, su realidad.

La pertinencia social de esta propuesta de mediación consiste en la concreción de una necesaria, urgente y renovada noción del aprendizaje desde la experiencia disruptiva e interacción con el entorno, propiciada y enriquecida por una mediación pedagógica cuyo motor inspirador sea, en sí, el descubrimiento y la observación de la realidad. Un modelo idóneo para detonar procesos de espacio-aprendizaje donde quienes aprenden conformen comunidades aprendientes en armonía con su entorno biofísico y social.

Algunas sendas que pueden conducir este abordaje de la realidad desde la dimensión pedagógica, como recurso expresivo, disruptivo e integrador, se citan a continuación:

a. La exploración y uso de otros lenguajes alternativos que privilegien lo lúdico, creativo y el goce estético, para expresar y recrear situaciones de la realidad social con una visión crítica.

b. La concepción de la realidad como una trama compleja de interconexiones y relaciones dinámicas ilimitadas.

c. La resignificación de la realidad y el entorno como valiosas fuentes de información y conocimiento.

d. La comprensión de la realidad como un fenómeno multidimensional, en el que, de forma simultánea, participan diversos actores, así como una gran variedad de condicionantes sociales.

e. La superación de paradigmas tradicionales que conciben el conocimiento fragmentado por áreas o asignaturas, al plantear propuestas más integradoras del conocimiento presente en el entorno.

f. La conciencia de que la construcción, la valoración y el reconocimiento de identidades y diversidades, en una realidad compleja, implica, necesariamente, la interrelación y conectividad con otros seres.

Desde un nuevo paradigma es necesario comprender que la pedagogía contemporánea requiere establecer nuevos referentes o puntos orientadores para alcanzar las condiciones que privilegien el desarrollo cognitivo y espiritual, en el cual se valore e integre el entorno físico y social de una realidad cada vez más compleja y que exige sincronía entre quienes la habitamos. 


\section{Referencias}

Alzate-Ortiz, F. A., Castañeda-Patiño, J. C. (2020). Mediación pedagógica: Clave de una educación humanizante y transformadora. Una mirada desde la estética y la comunicación. Revista Electrónica Educare, 24(1), 1-14. https://doi.org/10.15359/ree.24-1.21

Beltrán Villalva, M. (2016). Dramaturgia y hermenéutica: Para entender la realidad social. CIS. $\quad$ https://books.google.co.cr/books/about/Dramaturgia y hermen\%C3\%A9utica. html?id=Fz6 CwAAQBAJ\&printsec=frontcover\&source=kp read button\&redir esc $=\mathrm{y} \# \mathrm{v}=$ onepage $\& \mathrm{q} \& \mathrm{f}=\mathrm{false}$

Campos y Covarrubias, G. y Lule Martínez, N. E. (2012.). La observación, un método para el estudio de la realidad. Xihmai, 7(13), 45-60. https://dialnet.unirioja.es/servlet/ articulo?codigo $=3979972$

Cortés, M. C. (2016). El tiempo libre y el juego en la educación: Propuestas pedagógicas. Homo Sapiens Ediciones.

de la Torre, S. y Moraes, M. C. (2005). Sentipensar. Fundamentos y estrategias para reencantar la educación. Aljibe.

Dinello, R. A. (2006). Pedagogía de expresión ludocreativa. Revista Internacional Magisterio, 19, 1-13.

Flores Davis, L. E., Flores Gamboa, G. A., Jiménez Corrales, R. E., Madrigal, J. C. y M. Á. Perearnau Torras, M. (2009). Comunidad aprendiente. Ediciones Sanabria.

Freire, P. (2012). Pedagogía de la autonomía. Saberes necesarios para la práctica educativa. Siglo Veintiuno Editores.

Gómez Francisco, T. (2010). El nuevo paradigma de la complejidad y la educación: Una mirada histórica. Polis Revista Latinoamericana, 25, 1-14. http://journals.openedition.org/polis/400

González Parera, M. (2012). El teatro como estrategia didáctica. Barcelona: Universidad de Barcelona. https://cvc.cervantes.es/ensenanza/biblioteca ele/publicaciones centros/ PDF/argel 2012/04 gonzalez.pdf

Laferrière, G. (1999). La pedagogía teatral, una herramienta para educar. Educación social, 13, 5465. https://www.raco.cat/index.php/EducacioSocial/article/view/144501/383474

Mañón, Q. y Lorente, X. (2003). L'acompanyament i l'educador social. En J. Planella y J. Vilar (Eds.), L'educació social: Projectes, perspectives i camins (pp. 225-231). Plenilini.

Marcelo, C. y Vaillant, D. (2008). Hacia una formación disruptiva de docentes: 10 claves para el cambio. Narcea. 
Martínez Miguélez, M. (2009). Hacia una epistemología de la complejidad y transdisciplinariedad. Utopía y Praxis Latinoamericana, 14(46), 11-31. https://www.redalyc.org/articulo. oa? id $=27911855003$

Menchén Bellón, F. (2015). La necesidad de escuelas creativas: La escuela galáctica. Una nueva conciencia. Ediciones Díaz de Santos.

Miranda Calderón, L. A. (2015). Biotiempo y aprendizaje [Tesis doctoral inédita]. Universidad de La Salle, San José, Costa Rica.

Miranda Calderón, L. A. (2018). Juego escénico y expresión: Un abordaje lúdico de la realidad en la mediación pedagógica. En P.García Sempere, B. Montiano Benítez, A. I.Tejada Muñozy P.Tejada Romero (Coords.), Investigación y docencia de la creatividad desde una perspectiva interdisciplinar (pp. 381-393): Editorial Universidad de Granada. http://cicreart.com/publicaciones/

Miranda Calderón, L. A. y Cubillo Jiménez, K. (2010). Sensibilización y disposición al cambio, a la luz de los retos y desafíos de la actual coyuntura educativa. Revista Electrónica Educare, 14(2), 173-185. http://doi.org/10.15359/ree.14-2.12

Miranda Calderón, L. A., Vásquez, E. y Rosabal, S. (2017). Arte y expresión lúdica en el caleidoscopio de estilos de aprendizaje: Una propuesta innovadora para la formación de docentes de Educación Primaria en la Universidad Nacional de Costa Rica. En L. Miranda, P. Alves, C. Morais y D. Barros (Orgs.), Estilos de aprendizagem e Inovação pedagógica (pp. 43-58). Whitebooks.

Monroy, M., Torres D. y Jiménez, A. (2016). Epistemología: La complejidad del conocimiento educativo. Revista Xihmai, 11(22), 7-28. http://www.lasallep.edu.mx/xihmai/index.php/ xihmai/article/view/267/241

Moreno González, A. (2016). La mediación artística. Arte para la transformación social, inclusión social y el desarrollo comunitario. Ediciones Octaedro.

Navarro Solano, M. R. (2007). Drama, creatividad y aprendizaje vivencial: Algunas aportaciones del drama a la educación emocional. Cuestiones Pedagógicas, 18, 161-172. http:// institucional.us.es/revistas/cuestiones/18/10\%20drama,\%20creatividad.pdf

Pérez-Aldeguer, S. (2017). Las artes escénicas como metodología educativa en la educación superior. Foro de Educación, 15(22), 1-7. https://dialnet.unirioja.es/servlet/ articulo?codigo $=5903798$

Vázquez Lomelí, C. M. (2009). Pedagogía teatral. Una propuesta teórico-metodológica crítica. Calle 14. Revista de investigación en el campo del arte, 3(3), 60-73. https://dialnet.unirioja. es/servlet/articulo?codigo $=3231745$

Vieites, M. F. (2017). La pedagogía teatral como ciencia de la educación teatral. Educação \& Realidade, 42(4), 1521-1544. https://doi.org/10.1590/2175-623662918 